\title{
SMARTHOME ENERGY SAVER DENGAN PENGGABUNGAN SENSOR LDR, PIR, SUARA, DAN TEMPERATURE UNTUK MEREPRESENTASIKAN KONDISI RUANGAN SEBAGAI PERANGKAT PENGHEMAT ENERGI LISTRIK YANG DIGUNAKAN DALAM MASYARAKAT
}

\author{
Andri Kurniawan ${ }^{1, \dagger}$, Bayu Rukmana Jati ${ }^{1}$, Nada Ayunita Sunarto ${ }^{1}$ \\ ${ }^{1}$ Program Studi Fisika, Fakultas Sains dan Teknologi, Universitas Islam Negeri Syarif Hidayatullah \\ Jakarta \\ †corresponding author: andrikwn21@gmail.com
}

\begin{abstract}
Abstrak. Smarthome Energy Saver adalah sebuah alat pengontrol alat elektronik konvensional yang bertujuan untuk menghemat pemakaian energi listrik. Alat ini menggunakan berbagai macam sensor seperti: PIR, DHT22, Microphone, dan LDR. Sensor tersebut akan membaca keadaan ruangan dan datanya akan dikirmkan ke mikrokontroller melalui bluetooth untuk diproses. Hasil prosesnya akan dikirimkan menuju relay yang dihubungkan dengan alat elektronik untuk memutuskan aliran arus listrik alat elektronik tersebut agar mati secara otomatis saat tidak ada manusia dalam ruangan dan atau mencegah dinyalakan kembali saat kondisi yang telah diatur pengguna dalam mikrokontroller belum terpenuhi, walaupun dinyalakan secara manual.
\end{abstract}

Kata kunci: alat elektronik, energi listrik, sensor

Abstract. Smarthome Energy Saver is a device to control the conventional electric apparatus intended for saving the usage of electrical energy. This device using a variety of sensors such as: PIR, DHT22, Microphone, and LDR. The sensor will read the room condition and the data will be delivered to the microcontroller device with bluetooth to be processed. The result of the process will be sent to the relay that connected to the electric devices to disconnect the electric current from the electronic means to automatically off and / or pevent it to be turned on again when the condition that users have set didn't met, although it is turned on manually.

Keywords: electrical energy, electric device, sensor

\section{PENDAHULUAN}

Kesibukan masyarakat modern memang dapat membuat seseorang kehabisan waktunya untuk mengembalikan dan menata sesuatu seperti semula. Belakangan ini, untuk sekedar mematikan alat elektronik yang sudah tidak dipakai saja tidak dapat dilakukan dengan alasan waktu dan kesempatan. Remote control yang tidak diketahui keberadaannya, malas untuk berjalan menuju saklar di pojok ruangan, dan tidak adanya keberanian untuk berjalan ke dalam ruangan sendiri juga dapat menjadi alasan yang menunjang alat-alat elektronik dibiarkan menyala sepanjang waktu tanpa penghuni.

Hal ini memang tidaklah terlalu krusial untuk jangka pendek karena ada kalanya ruangan tersebut akan dipakai kembali dan terdapat (jika ada) petugas yang datang mematikan alat-alat tersebut. Akan tetapi, bisa menjadi yang paling penting jika dilakukan terus menerus dalam jangka waktu yang lama. Bayangkan saja jika kita selalu melihat tagihan listrik yang terus meningkat, atau alat elektronik yang mudah rusak, dan yang lebih luas lagi adalah menipisnya sumber daya alam yang tak terbarukan. Bahkan, sudah banyak pula berita kejadian yang menampilkan peristiwa kebakaran akibat konsleting arus listrik. 
Kebiasaan ini sudah hampir melekat pada diri manusia modern pada umumnya. Padahal, sudah banyak anjuran dan himbauan dari pemerintah daerah dan pusat ataupun oleh masyarakat lainnya untuk berhemat dan bijak menggunakan alat elektronik seperti: selalu mematikan kran air sehabis digunakan, mencabut kontak listrik agar tidak terjadi 'vampir listrik' dari alat-alat elektronik yang siaga, dan tidak menyalakan lampu pada siang hari. Akan tetapi, untuk mengubah kebiasaan tersebut diperlukan waktu yang cukup lama dan usaha yang sangat besar. Maka dari itu, penulis berusaha membuat alat yang disebut "Smarthome Energy Saver" dapat membantu menghemat energi yang terpakai oleh alat-alat listrik selagi proses menghilangkan kebiasaan ini masih berlangsung. Alat yang sederhana untuk membantu meminimalisir pemborosan yang terjadi.

\section{METODE PEMBUATAN ALAT}

\section{Flowchart}

Berikut ini adalah diagram alir (flowchart) dari rancangan alat smarthome yang akan dibuat:

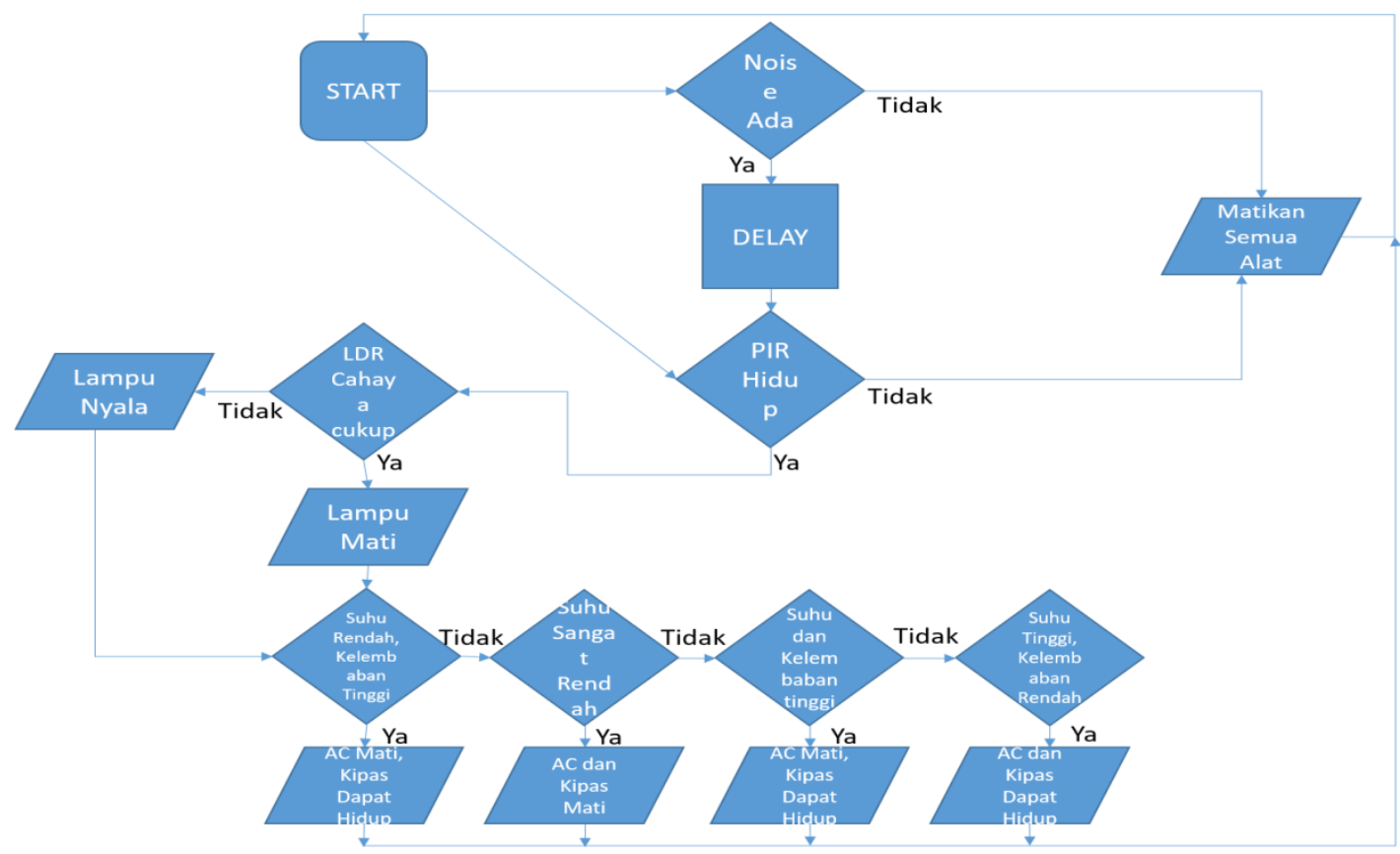

GAMBAR 1. Flowchart Smarthome Energy Saver

\section{Spesifikasi Alat}

Spesifikasi alat yang akan dibuat adalah sebagai berikut:

$\checkmark$ Menggunakan sensor cahaya LDR untuk mendeteksi keadaan cahaya sekitar apakah cahaya cukup atau tidak.

$\checkmark$ Menggunakan sensor suara (mic onboard amplifier) untuk mendeteksi suara dan noise acak terhadap lingkungan sekitar.

$\checkmark$ Sensor PIR sebagai sensor gerakan menggunakan HC-SR501 yang digunakan untuk mendeteksi keberadaan manusia.

$\checkmark$ Sensor DHT 22 sebagai sensor suhu berguna untuk mengontrol alat listrik yang digunakan terhadap suhu ruangan. 
$\checkmark$ Bluetooth HC-05 sebagai pemantau untuk mentransfer data dari mikrokontroller ke alat monitor.

$\checkmark$ Mikrokontroller Arduino Uno R3 dengan chip IC ATMega 328 sebagai unit pemroses data.

$\checkmark$ Satu buah resistor pada rangkaian LDR untuk menyangga tegangan berlebih.

$\checkmark$ Dua buah kapasitor 3uF/16V sebagai filter tegangan pada Supply.

$\checkmark$ Dua buah Relay jenis DPST sebagai saklar listrik yang diatur mikrokontroller untuk memutus/menyambungkan antara sumber listrik dengan alat elektronik.

$\checkmark$ Satu buah laptop sebagai alat monitor.

\section{Model Rancangan Sistem dan Rangkaian}

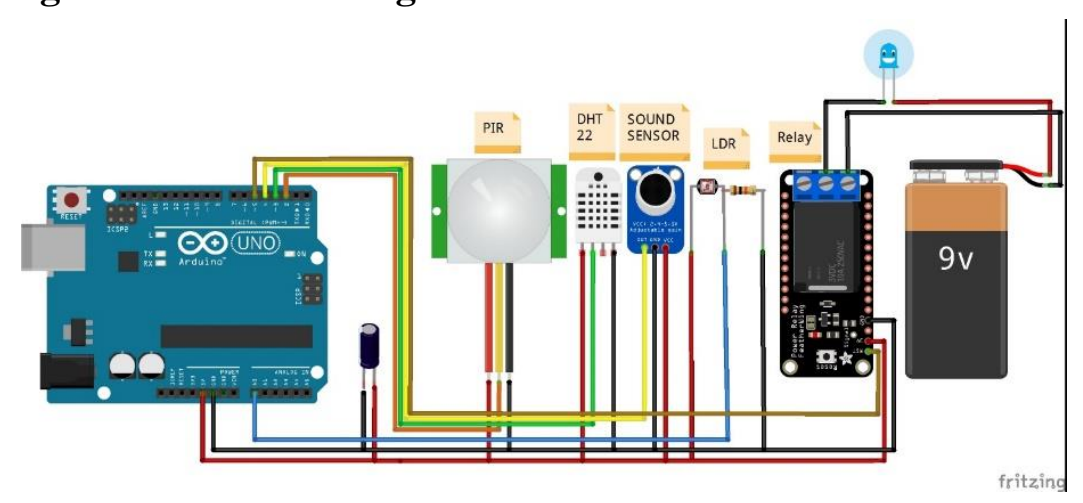

GAMBAR 2. Skematik Rangkaian Smarthome Energy Saver

Gambar 2 adalah rangkaian dari sistem smarthome yang akan dibuat. Alat tersebut diletakan di dalam ruangan buatan (dapat di bagian luar). Dari alat tersebut, sensor-sensor yang telah dipasang akan membaca kondisi lingkungan sekitar. Hal ini juga termasuk kepada alat elektronik di dalam ruangan tersebut. Sensor DHT akan membaca suhu dan kelembaban dalam ruangan, sensor PIR dan noise akan membaca pergerakan dan suara manusia, sementara sensor LDR akan membaca keadaan cahaya di dalam ruangan. Data yang dihasilkan sensor-sensor tersebut akan diperoleh sebagai masukan pada mikrokontroller Arduino.

Setelah data diproses oleh mikrokontroller, mikrokontroller akan memberikan perintah kepada relay untuk alat-alat elektronik sesuai dengan keterkaitan alat elektronik tersebut terhadap sensor yang dimiliki smarthome (Seperti lampu terhadap LDR). Di samping itu, bluetooth juga akan mengirimkan laporan dari data yang terbaca oleh sensor dan perintah yang diberikan mikrokontroller terhadap relay kepada gawai pengontrol. Laporan tersebut bersifat opsional yang berguna untuk kontrol alat dan deteksi kerusakan.

Sesuai dengan tujuan utama dari alat ini adalah untuk menonaktifkan alat elektronik saja, kecuali lampu. Oleh karena itu, alat Smarthome ini tidak difungsikan untuk otomatisasi alat elektronik dan keamanan. Hal ini dikarenakan faktor bahwa sensor yang digunakan utamanya berfungsi untuk mendeteksi keberadaan manusia di dalam ruangan. Karena jika difungsikan sebagai alat otomatisasi, maka alat elektronik selain lampu (AC, Kipas, dan lain-lain) akan menyala bahkan ketika ada manusia yang masuk ruangan tersebut hanya sekedar untuk mengambil barang yang tertinggal selama beberapa detik saja.

\section{PENGUJIAN DAN ANALISIS}

Sebelum melakukan finishing pada alat ini, penulis menguji alat terlebih dahulu dengan menggunakan program yang telah dibuat. Pada pengujian ini, hanya menggunakan sensor LDR dan PIR sebagai acuan. Sesuai fungsi, Sensor PIR akan mendeteksi gerakan penguji di area jangkauan sensor, sementara sensor LDR akan mendeteksi nilai cahaya yang ada di lingkungan sekitar. 
Sebelum itu, pada program diberikan nilai acuan untuk LDR sebagai kecukupan cahaya pada ruangan. Pada saat pengujian, cahaya akan dikatakan cukup apabila melebihi nilai 300 output dari LDR pada monitor arduino. Setelah itu, output yang dikeluarkan mikrokontroller akan diaplikasikan dengan menggunakan LED.

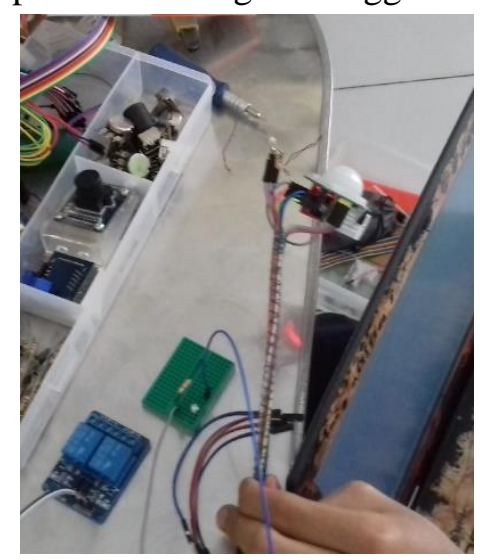

(a)

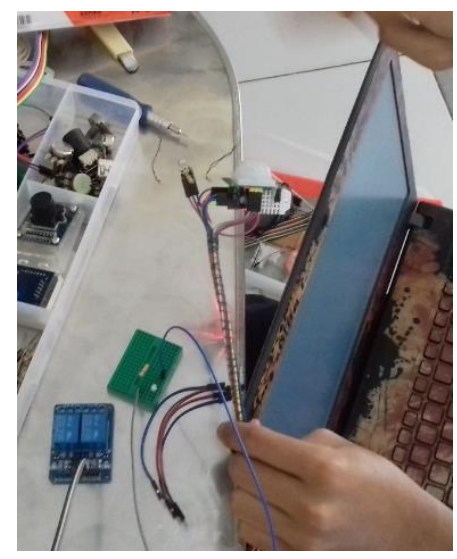

(b)

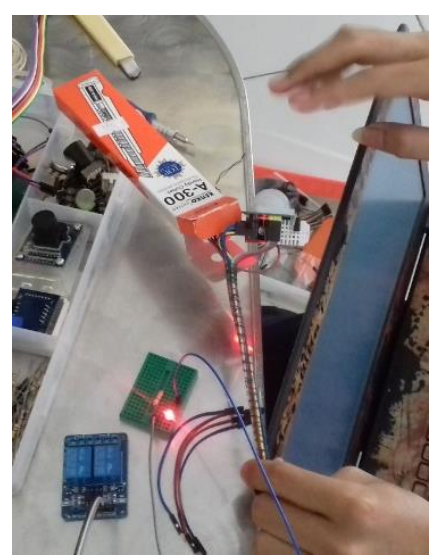

(c)

GAMBAR 3. (a) Keadaan saat tidak ada gerakan dan cahaya cukup, (b) Keadaan saat ada gerakan dan cahaya cukup, dan (c) Keadaan saat ada gerakan dan cahaya tidak cukup

Dari ketiga gambar diatas dapat dilihat bahwa pada gambar pertama keadaan LED pada keadaan mati ketika tidak terdapat gerakan yang dideteksi oleh sensor PIR dan cahaya masih cukup terang (nilai > 300). Sedangkan pada gambar kedua, sensor PIR mendeteksi gerakan namun, cahaya masih cukup terang (nilai > 300). Pada keadaan itu, lampu LED tetap mati. Sementara gambar ketiga, sensor PIR mendeteksi gerakan dan LDR ditutup agar cahaya menjadi tidak cukup. Pada keadaan ini, lampu LED menyala terang.

Analisis dari pengujian ini adalah, alat yang digunakan memiliki kecepatan respon yang rendah. Sehingga, tampilan nilai dan kondisi dapat berubah dengan jeda waktu tertentu sekitar 2 detik. Data yang dihasilkan terekam pada panel monitor arduino, sehingga kesalahan sistem dapat diperbaiki secara instan. Namun, tanpa alat monitor pun alat bisa bekerja sendiri. Walau demikian, tanpa monitor adalah sama dengan alat tidak terkontrol dan saat rusak/ada kesalahan maka alat akan sulit untuk diperbaiki.

\section{KESIMPULAN}

Berdasarkan hasil pengujian dan pembahasan dapat ditarik kesimpulan sebagai berikut: 
Untuk membuat alat Smarthome Energy Saver diperlukan sensor-sensor seperti sensor PIR, DHT, sensor suara, dan LDR sebagai pengambil data lingkungan sekitar dan pengontrol kerja mikrokontroller.

$>$ Untuk monitoring, diperlukan perangkat bluetooth untuk mengirimkan data dari mikrokontroller ke alat monitoring agar kondisi dan keadaan Smarthome aman terkendali.

$>$ Masing-masing sensor memiliki daerah kerja yang berbeda pada setiap alat elektroniknya. Setiap output sensor akan dihubungkan ke relay yang berbeda agar memungkinkan mikrokontroller mengontrol alat elektronik tersebut.

> Dengan adanya sensor untuk monitoring, setiap alat yang tidak perlu digunakan dan atau berbahaya tidak akan bisa dinyalakan walaupun dengan cara manual. Sehingga, daya listrik yang digunakan akan menjadi lebih sedikit.

\section{REFERENSI}

[1] Adhi Triyanto, Media Pembelajaran Sensor Pir Parallax, Hall Effect, Dan Sensor Ds18b20 Pada Mata Pelajaran Sensor Dan Aktuator Di Smk Muhammadiyah Prambanan. Hal. 21-22, 2016.

[2] Ada, Lady, How PIRs Work. Diambil dari: https://learn.adafruit.com/pir-passive-infraredproximity-motion-sensor/how-pirs-work (16 Februari 2018), 2014.

[3] Handayani, Ageng Sari dkk, Komunikasi Data Lewat Bluetooth (Depok: Universitas Gunadharma. Hal. 3-6, 2005)

[4] Nedelkovski, Dejan, DHT11 \& DHT22 Sensors Temperature and Humidity Tutorial using Arduino. Diambil dari: http://howtomechatronics.com/tutorials/arduino/dht11-dht22-sensorstemperature-and-humidity-tutorial-using-arduino/ (15 Februari 2018), 2016.

[5] Nedelkovski, Dejan, Arduino and HC-05 Bluetooth Module Tutorial. Diambil dari: http://howtomechatronics.com/tutorials/arduino/arduino-and-hc-05-bluetooth-module-tutorial/ (15 Februari 2018), 2016.

[6] Setiawan, Iwan, Buku Ajar Sensor Dan Tranducer (Semarang: Fakultas Teknik Diponegoro, 2009)

[7] Sri Supatmi, Pengaruh Sensor LDR Terhadap Pengontrolan Lampu. Bandung: Jurnal Majalah Ilmiah Unikom. Vol.8, Hal. 175-178. Diambil dari: http://jurnal.unikom.ac.id/jurnal/pengaruhsensor-ldr-terhadap.1n/volume-82-artikel-5.pdf (15 Februari 2018), 2011.

[8] Syam, Rafiuddin, Seri Buku Ajar: Dasar-Dasar Teknik Sensor (Makassar: Fakultas Teknik Universitas Hasanuddin, 2013)

[9] Yusuf, Akira, Erika, Makalah Sensor PIR (Hal. 13, 2014) 